\title{
Role of Cartridge Based Nucleic Acid Amplification Test in Diagnosing Tuberculous Empyema Thoracis - A Study from Telangana, India
}

\author{
Gaddam Ramulu Yadav¹, Vankayala Veena Reddy², Pampana Eshwaramma ${ }^{3}$, Tarigopula Pramod Kumar, \\ Mandarakala Gopala Krishna Murthy5 ${ }^{5}$ Peruka Kiran Kumar6 \\ 1, 2, 3, 4, 5, 6 Department of Pulmonary Medicine, Gandhi Medical College, Secunderabad, Telangana, India.
}

\section{ABSTRACT}

\section{BACKGROUND}

The pleura is involved in pulmonary or systemic tuberculosis by various mechanisms like delayed hypersensitivity. Tuberculous empyema usually results from failure of a primary tubercular effusion to resolve and further progresses to chronic suppurative form. In tuberculous empyema, the pleural fluid is purulent, and is loaded with tuberculous organisms on direct acid-fast bacillus (AFB) smear examination and / or culture of pus. We need to assess the role of cartridge based nucleic acid amplification test (CBNAAT) in the diagnosis of tuberculous empyema.

\section{METHODS}

This study was a prospective observational study of all adult patients of empyema above 15 years of age, admitted in the Department of Pulmonology, over a period of 1 year, 6 months after obtaining clearance from ethical committee and proper consent from the study subjects.

\section{RESULTS}

A total of sixty-three (63) empyema cases were recruited and analysed further. On evaluation, we diagnosed 26 cases with tubercular aetiology (41.27\%) and remaining thirty-seven (58.73\%) cases with non-tubercular aetiology.

\section{CONCLUSIONS}

Pleural fluid (pus) cartridge based nucleic acid amplification test (CBNAAT) is very sensitive and provides a rapid confirmed diagnosis within 2 hrs. including drug susceptibility. In this study, sensitivity of CBNAAT in suspected tuberculous empyema patients was $88.5 \%$ and specificity was $100 \%$. Pleural fluid CBNAAT is more sensitive in both pleural fluid AFB smear positive (100\%) and pleural fluid AFB smear negative (72.7 \%) cases. So, pleural fluid and sputum direct AFB smear and CBNAAT should be sent in all suspected tuberculous empyema cases for early diagnosis of tuberculosis and early detection of rifampicin resistance.

\section{KEY WORDS}

Mycobacterium Tuberculosis, Tubercular Empyema, Pleural Fluid, CBNAAT, AFB, Anti-Tubercular Drugs
Corresponding Author: Dr. Vankayala Veena Reddy, Assistant Professor,

H. No. 12-13 - 483 / $27 / 1$; Street No. 1, Tarnaka, Secunderabad,

Hyderabad - 500017, Telangana, India. E-mail: veena.vankayala1@gmail.com

DOI: 10.14260/jemds/2021/348

How to Cite This Article:

Yadav GR, Reddy VV, Eshwaramma P, et al. Role of cartridge based nucleic acid amplification test in diagnosing tuberculous empyema thoracis - a study from Telangana, India. J Evolution Med Dent Sci 2021;10(22):1680-1685, DOI: $10.14260 /$ jemds/2021/348

Submission 23-12-2020,

Peer Review 22-03-2021,

Acceptance 29-03-2021,

Published 31-05-2021.

Copyright (C) 2021 Gaddam Ramulu Yadav et al. This is an open access article distributed under Creative Commons Attribution License [Attribution 4.0 International (CC BY 4.0)] 


\section{BACKGROUND}

Tuberculosis is caused by Mycobacterium tuberculosis (MTB) which is a gram positive, aerobic, acid \& alcohol positive bacillus. MTB transmission occurs by the inhalation of droplet nuclei. Droplet nuclei which are 1 - 5 microns and freshly produced by coughing or sneezing, can give rise to TB infection. ${ }^{1}$ In many regions of the world where TB is more common, TB pleural effusion maintains its position as the leading inflammatory pleural disease. In fact, pleural disease is one of the most common extra pulmonary involvement in TB in developing countries like India 1,2,3 Empyema thoracis, defined as collection of pus in the pleural space. Empyema is an illness with significant morbidity, and mortality. ${ }^{4}$ Tuberculous empyema constitutes approximately $20 \%$ of all empyema cases, in countries where prevalence of TB is high for example, India.,2,5 Tuberculous empyema is an entity distinct from and less common than, TB pleural effusion. In contrast to delayed hypersensitivity leading to pleural fluid accumulation in a TB pleural effusion, TB empyema is characterized by chronic, MTB infection of the pleural space. ${ }^{1}$ Tuberculous empyema usually results from failure of a primary tubercular effusion to resolve and further progress to chronic suppurative form ${ }^{1}$ and in some cases due to extension of infection from intrathoracic lymphnodes ${ }^{6}$ or a sub diaphragmatic focus or haematogenous spread. ${ }^{1}$

In many patients with chronic TB empyema, the inflammatory process may be present for years with a paucity of clinical symptoms. Other patients may present with low grade fever, night sweats and constitutional symptoms, such as fatigue and weight loss. Patients often have respiratory symptoms for several months prior to diagnosis.1,7,8,9 In tuberculous empyema the pleural fluid is purulent and is loaded with tuberculous organisms on direct AFB smear examination and / or culture of pus. Pleural fluid cell counts usually exceed $100000 / \mathrm{mm} 3$, with virtually all cells being neutrophils. The pleural fluid has low glucose [usually below $20 \mathrm{mg} / \mathrm{dl}$ ] and high protein concentration [usually more than $5 \mathrm{~g} / \mathrm{dl}$ ], and is acidic [with $\mathrm{pH}$ usually below 7.20.1,10,11,12 The principles of treatment, pleural space drainage, and antimicrobial chemotherapy are similar for bacterial and TB empyema. ${ }^{13,14} \mathrm{~TB}$ empyema initially can be curative with serial thoracentesis and anti TB therapy. ${ }^{13,14}$ In contrast to primary tuberculous pleural effusion, which does not require surgery, TB empyema is usually accompanied by thick pleural fibrous scar tissue and requires surgical intervention. ${ }^{15,16}$ These patients have a tendency to develop multi drug resistant organisms because the anti TB drugs frequently do not reach their normal levels in the pleural space due to thick fibrous and / or calcified pleura. ${ }^{17}$

Surgical procedures ${ }^{18,19,20}$ include standard decortication, (limited to the parietal sides of the empyema collection). If the affected lung is grossly destroyed or fails to expand after decortication, resection of the entire lung along with TB empyema may be needed. After resection muscle flaps are used to obliterate the residual space, to prevent Broncho pleural fistula (BPF) and buttress the bronchial stump. Other procedures are Thoracoplasty, ${ }^{18}$ Plombage therapy, parietal wall collapse, open drainage. Presence of BPF, chronic duration of disease and presence of disease in the underlying and / or contra lung contributes to a poor outcome with the treatment. Improvement of lung function after treatment depends on the relative lung volume of the affected side, and the volume of empyema. ${ }^{1}$

The objective was to assess the role of CBNAAT in the diagnosis of tuberculous empyema.

\section{METHODS}

This study was a prospective observational analysis of all adult cases of tuberculous empyema admitted in the department of pulmonary medicine of Gandhi Hospital, Secunderabad, over a period of 1 year 6 months (Mar 2017 - Sep 2018) after obtaining clearance from the ethical committee and proper consent from study subjects. 63 adult patients ${ }^{21}$ with the age group of more than 15 years (15 to 70 years) who were admitted with the diagnosis of empyema were included in the study. Out of them 26 cases were diagnosed as tuberculous empyema and they were analysed further.

\section{Inclusion Criteria}

- Patients of both sex and age of more than 15 years

- Medical history compatible with tuberculous pleural effusion

- Pleural effusion by clinical examination, Chest X ray and Ultrasonography

- Exudative pleural effusion by Light's criteria. ${ }^{11}$

- Pleural effusion patients with pulmonary or extra pulmonary TB.

\section{Exclusion Criteria}

- Post traumatic and Post-Operative Empyema

- Unwilling patients.

- Immunocompromised patients like HIV

- Synpneumonic or Parapneumonic effusion,

- Malignant pleural effusions

- Transudative effusions (based on light's criteria) ${ }^{11}$

- Undiagnosed pleural effusions after complete workup

\section{Case Definition}

"TB empyema" characterized by asymptomatic pleural effusion to ${ }^{22}$ massive, frankly purulent involvement of the pleural space with BPF and trapping of the lung that is loaded with tuberculous organisms on AFB smear staining. The diagnosis is confirmed after thoracocentesis by finding grossly purulent pleural fluid that is smear positive for AFB and MTB detected in CBNAAT and / or chest $\mathrm{x}$ - ray and / or CT chest lesions consistent with active pulmonary tuberculosis.

\section{Investigations}

Direct examination of sputum smear for AFB, sputum for CBNAAT, Pleural fluid for direct smear examination for AFB and CBNAAT for MTB, chest $\mathrm{x}$ - ray, CT chest, ${ }^{23}$ USG chest, HIV screening and routine investigations like RFT, LFT, CBP, ESR, 
ECG and other required investigations. Radiological findings suggestive of tuberculosis are nodular consolidation with or without cavity, tree in bud appearance.

\section{Procedure $3,23,24,25$}

All patients who came to OPD and casualty and who fulfilled the inclusion criteria were considered for this study after taking thorough clinical history and required investigations. Then evaluation of parameters such as age, sex, symptoms with duration and co morbidities were done. Chest $\mathrm{X}$ - ray (CXR) was done in all patients at the time of admission. Followup CXRs were done when needed like after insertion of Inter Costal Tube Drain (ICTD), at the time of ICTD removal and at the time of discharge. Ultrasound chest and CT chest were also done when needed.

Thoracentesis was done with strict aseptic precautions under local anaesthesia to collect Pleural fluid. It was sent for gram stain, anaerobic and aerobic culture to exclude concomitant bacterial infection, direct smear examination for AFB by fluorescent auramine and rhodamine stain, CBNAAT for MTB. Pleural fluid was also sent for Pathological analysis (TLC, differential leucocyte count) and Biochemical analysis (pleural fluid protein, sugar, and Lactate Dehydrogenase (LDH). Pleural fluid was not sent for Adenosine deaminase (ADA) test as it was elevated in empyema of any aetiology. Because of high cost, time consuming and low sensitivity, AFB culture of pleural fluid was not included in this study protocol.

Sputum for AFB smear and CBNAAT for MTB were done in all tuberculous empyema patients. Intercostal tube was inserted to drain the pus by closed tube thoracostomy (straight chest tube - Romson 28G to $32 \mathrm{G}$ ) with a water seal drainage system.

\section{CBNAAT ${ }^{6,7,8}$ (Cepheid, GeneXpert - IV Processing Unit)}

Designed to extract, amplify by rapid real-time PCR and identify targeted rpoB nucleic acid sequences in the TB genome, in sputum \& specimens from extra pulmonary sites. CBNAAT is useful in detecting Mycobacterium tuberculosis accurately and rapidly and also identifying drug resistance conferring mutations. 6,7

\section{Principle of CBNAAT}

There are nucleic acid probes - Molecular beacons that help us identify the presence or absence of rifampicin - susceptible wild - type by recognizing the sequence of rpoB gene, thus identifying rifampicin resistance. Fluorescent light indicates rifampicin susceptible TB - meaning there is a match between nucleic acid probe and gene sequence. No fluorescence indicates absent rifampicin resistance.

\section{Major Advantages}

- $\quad$ Single-use disposable Cartridge, containing all necessary elements, automated sample preparation, amplification detection.

- $\quad$ Provides results from unprocessed samples.

- $\quad$ Digital read outs within 2 hours.
- Sensitivity close to culture and sensitivity for TB in adults $=88 \%$ (98\% for smear positive TB, $68 \%$ for smear negative TB, $79 \%$ in HIV +ve) and Specificity $=98 \%$.

- $\quad$ R - Resistance: Sensitivity $=95 \%$; specificity $=98 \%$.

- No bio-safety cabinet.

\section{Test Procedure}

Affix the sample ID to the side of the cartridge. The collected specimens are mixed with reagent (elution bottle contents). Vigorously shake sample vial contents 20 times. Return vial to rack and incubate at room temperature for 15 minutes. With 5 minutes remaining re shake the contents of vial 20 times. Pipette Two $\mathrm{ml}$ of the processed sample opening on Xpert cartridge. Place cartridge on tray, to start the process. Fluorescent signals are used to interpret the results. Higher and Lower DNA template load is represented as lower and higher Ct values respectively. CBNAAT results are interpreted as high (16), medium (16 - 22), low (22 - 28), very low (> 28).

\section{Interpretation of Results 23,24}

CBNAAT results are interpreted as, microbiologically confirmed drug sensitive case of tuberculosis if result shows M. tuberculosis detected and rifampicin sensitive. We have to repeat on a second specimen if the result comes as $M$. tuberculosis detected but rifampicin indeterminate. Consider multi-drug resistant (MDR) treatment if the result comes as $M$. tuberculosis detected and rifampicin resistance. Alternate diagnosis considered if the result comes as M. tuberculosis is not detected. If the result comes as invalid, CBNAAT test has to be repeated on the second specimen, repeat CBNAAT on the same sample if the result shows error / no result.

\section{Statistical Analysis}

Data was analysed by using MS Excel, open epi info software results are shown, and Inferential Statistics obtained included chi Square Test and P Values. $\mathrm{P}<0.05$ was considered statistically significant. Comparison within groups was performed by t test, as appropriate.

\section{RESULTS}

In the present study a total of 63 empyema patients were included who attended the Department of Pulmonary Medicine, Gandhi Hospital. Out of 63 empyema cases, patients with non-tuberculous empyema were 37 (58.73\%) and patients with tuberculous empyema were 26 (41.27\%). Tuberculous patients presented at the mean age of 31.5 (Table 1). Type 2 Diabetes mellitus was found in 4 patients $(15.38 \%)$ and hypertension found in 2 patients (07.14\%). Among 26 patients, 8 patients were smokers.

Among 26 patients with tuberculous empyema males were 22 in number (84.62\%) and females 4 (15.38\%). In the present study majority of tuberculous patients were males (Table 2). In this study among 26 Tuberculous empyema patients, AFB detected in direct sputum smear examination in $10(38.46 \%)$ patients and MTB detected in CBNAAT in sputum samples in 16 (61.53\%) patients. Among 26 tuberculous empyema patients, AFB detected direct smear of Pleural fluid in 15 Cases (57.69\%) and pleural fluid for CBNAAT, MTB was 
detected in 23 cases (88.46 \%) [Table 3]. Among 26 tuberculous empyema cases pleural fluid i.e., pus for gram staining was positive in 7 cases, but culture was negative in all these cases.

\begin{tabular}{|c|c|c|c|c|}
\hline \multirow{2}{*}{$\begin{array}{l}\text { Age Groups } \\
\text { (in Years) }\end{array}$} & \multicolumn{2}{|c|}{$\begin{array}{c}\text { Empyema with Koch's } \\
\text { Aetiology }\end{array}$} & \multicolumn{2}{|c|}{$\begin{array}{c}\text { Empyema with } \\
\text { Non-Koch's Aetiology }\end{array}$} \\
\hline & No. of Cases & $\%$ & No. of Cases & $\%$ \\
\hline $15-20$ & 2 & (7.69\%) & 2 & $(5.40)$ \\
\hline $21-30$ & 10 & (38.46 \%) & 4 & (10.81\%) \\
\hline $31-40$ & 7 & $(26.92 \%)$ & 10 & $(27.0 \%)$ \\
\hline $41-50$ & 3 & (11.53 \%) & 12 & (32.43\%) \\
\hline $51-680$ & 2 & (7.69\%) & 4 & (10.81 \%) \\
\hline $61-70$ & 2 & (7.69\%) & 5 & (13.5\%) \\
\hline Total & 26 & & 37 & \\
\hline \multicolumn{5}{|c|}{$\begin{array}{l}\text { Table1. Age Distribution of Tuberculous \& } \\
\text { Non-Tuberculous Empyema (Total 63) }\end{array}$} \\
\hline
\end{tabular}

\begin{tabular}{|ccc|}
\hline Gender & No. of Cases & Percentage \\
Male & 22 & $84.62 \%$ \\
Female & 4 & $15.38 \%$ \\
Total & $\mathbf{2 6}$ & $\mathbf{1 0 0}$ \\
\hline Table 2. Gender Distribution of Tuberculous Empyema \\
\hline
\end{tabular}

\begin{tabular}{|ccc|}
\hline Investigation & No. of Cases & Percentage \\
\hline Pus For AFB smear positive & 15 & $57,69 \% \%$ \\
Sputum For AFB smear positive & 10 & $38.46 \%$ \\
Sputum For CBNAAT for MTB MTB detected & 16 & $61,53 \%$ \\
Past History of TB & 11 & $42.31 \%$ \\
Radiological Findings S / O PTB & 14 & $53.84 \%$ \\
Pus For CBNAAT for MTB MTB detected & 23 & $88.46 \%$ \\
\hline Table 3. Microbiological \& Radiological \\
Diagnosis of Tubercular Empyema \\
\hline
\end{tabular}

In this study, pleural fluid for both direct smear examinations for AFB and CBNAAT for MTB were negative in 3 cases. In these 3 cases sputum for AFB smear positive and MTB detected in CBNAAT, and also radiologically consistent with active pulmonary tuberculosis. In this study one drug resistant TB was seen. Both pleural fluid and sputum showed rifampicin resistance by CBNAAT.

Sensitivity of pleural fluid CBNAAT, in pleural fluid AFB smear negative patients was $72.70 \%$, but in pleural fluid AFB smear positive patients, sensitivity of pleural fluid CBNAAT was $100 \%$. (Table 4)

\begin{tabular}{|ccc|}
\hline $\begin{array}{c}\text { Pleural Fluid } \\
\text { CBNAAT }\end{array}$ & $\begin{array}{c}\text { Pleural Fluid AFB } \\
\text { Smear Positive } \\
\text { (N = 15) }\end{array}$ & $\begin{array}{c}\text { Pleural Fluid AFB } \\
\text { Smear Negative } \\
\text { (N = 11) }\end{array}$ \\
$\begin{array}{c}\text { Pleural fluid CBNAAT } \\
\text { positive (N = 23) }\end{array}$ & $15(57.69 \%)$ & $8(30.76 \%)$ \\
$\begin{array}{c}\text { Pleural fluid CBNAAT } \\
\text { negative(N = 03) }\end{array}$ & 0 & $3(11.53 \%)$ \\
\hline \multicolumn{2}{|c|}{ Table 4. Diagnostic Yield of Pleural Fluid (Pus) } \\
& AFB Smear and CBNAAT \\
\hline
\end{tabular}

\begin{tabular}{|c|c|c|c|}
\hline Pleural Fluid & Positive & Negative & Total \\
\hline $\begin{array}{l}\text { For direct smear for } \\
\text { AFB }\end{array}$ & $15(57.69 \%)$ & $11(42.31 \%)$ & 26 \\
\hline For CBNAAT & $23(88.46 \%)$ & $3(11.54 \%)$ & 26 \\
\hline \multicolumn{4}{|c|}{$P$ value $0.01238 \mathrm{chi}$ square 6.256} \\
\hline Table 5. Microb & gical Diagn & uberculous & $(N-26)$ \\
\hline
\end{tabular}

In this study, out of 26 tuberculous empyema patients, pleural fluid smear for AFB was positive in 15 patients (57.69 $\%$ ) and negative in 11 patients (42.3\%). Pleural fluid CBNAAT detected MTB in 23 patients $(88.46 \%$ ) and negative in 3 patients (11.5\%). Higher proportion of patients have been picked up by pleural fluid CBNAAT which was statistically significant (P value 0.01238, chi square 6.256). (Table 5).

Overall diagnostic sensitivity and specificity of pleural fluid CBNAAT were found to be $88.5 \%$ and $100 \%$ respectively. ${ }^{16,18}$ [Table 6].

\begin{tabular}{|ccc|}
\hline $\begin{array}{c}\text { Pleural Fluid } \\
\text { CBNAAT } \\
\begin{array}{c}\text { Pleural fluid CBNAAT } \\
\text { positive }\end{array}\end{array}$ & $\begin{array}{c}\text { Empyema of Koch's } \\
\text { Aetiology (N = 26) }\end{array}$ & $\begin{array}{c}\text { Empyema of Non Koch's } \\
\text { Aetiology (N = 37) }\end{array}$ \\
$\begin{array}{c}\text { Pleural fluid CBNAAT } \\
\text { negative }\end{array}$ & 23 & 0 \\
\hline \multicolumn{2}{|c|}{ Sable 6. Sensitivity and Specificity of CBNAAT } \\
\hline
\end{tabular}

Out of 26 tuberculous patients in this study 3 patients were treated with thoracocentesis, 23 patients required Intercostal drainage tube (ICDT) and 11 patients required CT surgeon intervention. ${ }^{2,23,25,26}$ (Table 7)

\begin{tabular}{|ccc|}
\hline Treatment Modality & No & Percentage \\
Thoracocentesis & 3 & $11.53 \%$ \\
ICD & 23 & $88.46 \%$ \\
CT Surgeon Intervention & 11 & $42.30 \%$ \\
\hline Table 7. Treatment Modalities in Tuberculous Empyema Cases \\
\hline
\end{tabular}

\section{DISCUSSION}

In the present study total of 63 empyema patients were included and among them non-tuberculous empyema patients were $37(58.73 \%)$ and remaining 26 patients fulfilled the criteria of tuberculous empyema (41.27\%). In developing countries like India, Thoracic empyema continues to be an important cause of morbidity ${ }^{1}$.The same is reflected in this study (63 over an 18-month period). Indian studies reveal that tuberculosis accounts for a large number of empyema cases. ${ }^{15,16,19}(38.6$ - $65 \%)$ In this study also, tuberculous empyema accounted for 26 of the $63(41.27 \%)$ of total empyema cases (Table 1). But in western countries Pulmonary infections (like community acquired pneumonia, lung abscess) are the commonest causes $)^{2,5-9}$

Among 26 patients with tuberculous empyema males were 22 in number (84.62\%) and females 4 (15.38\%). In the present study majority of tuberculous patients were males. (84.61\%) (Table2). Tuberculous patients were presented at the mean age of 31.5. In this study, empyema of Koch's aetiology was more common in the younger age group (Table 1). Explanation for this could be that more young people work outdoors and are exposed to sputum smear positive cases more.

Most empyema patients of Koch's aetiology were associated with primary lesions like cavities. Sometimes the cavity may rupture into the pleural space, resulting in empyema or pyopneumothorax, which may be loaded with TB bacilli. This could be the reason for the high percentage of sputum and pleural fluid AFB smear positivity ${ }^{16,20}$ In this study, sensitivity of pleural fluid CBNAAT in suspected tuberculous empyema patients was $88.5 \%$ and specificity was $100 \%$ (Table 5).

Pleural fluid CBNAAT is more sensitive in both pleural fluid AFB smear positive (100\%) and pleural fluid AFB smear negative $(72.7 \%$ ) cases (Table 4$)$. This may be due to high bacillary load in tubercular empyema patients. 6,7

Another advantage of CBNAAT is its ability to identify drug resistance at the same time. In our study one drug resistant TB was seen. In this case, both sputum and pleural fluid, rifampicin resistance was identified by CBNAAT. 
Concomitant bacterial super infection was found in seven cases. In these, bacterial cultures were negative, positive only on gram stain.

Commonest co morbid illness associated in our study was Diabetes mellitus. Consolidation and cavity were the common pulmonary parenchymal lesions noted. Three (11.53\%) out of 26 tuberculous patients had presented with pyopneumothorax.

\section{CONCLUSIONS}

In developing countries like India, where prevalence of TB is high, MTB is a common cause of empyema, mainly affecting the young population. All patients of tubercular empyema have chronic morbidity and may require hospitalization and intercostal tube drainage as concluded from this study also. The most important aspect observed in this study is that looking for Mycobacterium tuberculosis bacteria (MTB) by direct smear or CBNAAT in pleural fluid as well as in sputum samples will enhance early diagnosis of tuberculous empyema. Most empyema patients of Koch's aetiology when treated early with anti-tubercular treatment and early drainage of pus have favourable outcome.

Difficulties specific to management of TB empyema include the inability of the trapped lung to re-expand adequately, protracted duration of illness, presence of significant incidence of BPF requiring complicated surgical procedures and failure to achieve therapeutic drug levels in pleural fluid, which can lead to drug resistance. ${ }^{22}$

CBNAAT is a useful rapid diagnostic tool for suspected tuberculous empyema patients. Pleural fluid (pus) CBNAAT is very sensitive and provides a rapid confirmed diagnosis within $2 \mathrm{~h}$ including drug susceptibility. In this study, sensitivity of CBNAAT in suspected tuberculous empyema patients was 88.5 $\%$ and specificity was $100 \%$. Pleural fluid CBNAAT is more sensitive in both pleural fluid AFB smear positive $(100 \%)$ and pleural fluid AFB smear negative (72.7\%) cases.

So, pleural fluid and sputum direct AFB smear and CBNAAT should be sent in all suspected tuberculous empyema cases. By this TB empyema cases are detected early along with drug resistance identification thus reducing morbidity and mortality.

Data sharing statement provided by the authors is available with the full text of this article at jemds.com.

Financial or other competing interests: None.

Disclosure forms provided by the authors are available with the ful text of this article at jemds.com.

The authors thank Dr. Ravindar, professor and HOD of the department of CT surgery, Dr P. Sri Hari professor and HOD of the department of radiology.

\section{REFERENCES}

[1] Sharma SK. Text book of Tuberculosis. $2^{\text {nd }}$ edn. Jaypee Brothers Medical Publishers 2009.

[2] Sinzobahamvya N, Bhakta HP. Pleural exudate in a tropical hospital. Eur Respir J 1989;2(2):145-8.
[3] Valdes L, Alvarez D, Valle JM, et al. The etiology of pleural effusions in an area with high incidence of tuberculosis. Chest 1996;109(1):158-62.

[4] Jess P, Brynitz S, Møller AF. Mortality in thoracic empyema. Scand J Thorac Cardiovasc Surg 1984;18(1):85-7.

[5] Sethy HK, Panda G, Trilochan BP, et al. Empyema thoracis: a current profile at a tertiary care center. J Evolution Med Dent Sci 2016;5(13):547-56.

[6] Kearney SE, Davies CW, Tattersall DJ, et al. The characteristics and significance of thoracic lymphadenopathy in parapneumonic effusion and empyema. Br J Radiol 2000;73(870):583-7.

[7] Gupta SK, Kishan J, Singh SP. Review of one hundred cases of empyema thoracis. Indian J Chest Dis Allied Sci 1989;31(1):15-20.

[8] Bai KJ, Wu IH, Yu MC, et al. Tuberculous empyema. Respirology 1998;3(4):261-6.

[9] Vardhan MV, Tewari SC, Prasad BNBM, et al. Empyema Thoracis-study of present day clinical and aetiological profile and management techniques. Ind $\mathrm{J}$ Tub 1998;45:155-60.

[10] Mukherjee S, Begum S, Kundu S, et al. Clinical profile of tubercular empyema with special reference to diagnostic role of CBNAAT. Journal of Clinical and Diagnostic Research 2017;11(10):0C01-5.

[11] Light RW. Text book of pleural diseases. $6^{\text {th }}$ edn. Lippinkott Williams and Wilkins 2013.

[12] Al-Kattan KM. Management of tuberculous empyema. Eur J Cardiothorac Surg 2000;17(3):251-4.

[13] Elliott AM, Halwiindi B, Hayes RJ, et al. The impact of human immunodeficiency virus on presentation and diagnosis of tuberculosis in a cohort study in Zambia. J Trop Med Hyg 1993;96(1):1-11.

[14] Neihart RE, Hof DG. Successful nonsurgical treatment oftuberculous empyema in an irreducible pleural space. Chest 1985;88(5):792-4.

[15] Khanna BK. Management of tuberculous empyema. Indian J Tuberc 1987;34:147-9.

[16] Mouroux J, Maalouf J, Padovani B, et al. Surgical management of pleuropulmonary tuberculosis. J Thorac Cardiovasc Surg 1996;111(3):662-70.

[17] Lahiri TK, Agrawal D, Gupta R, et al. Analysis of status of surgery in thoracic tuberculosis. Indian J Chest Dis Allied Sci 1998;40(2):99-108.

[18] Elliott AM, Berning SE, Iseman MD, et al. Failure of drug penetration and acquisition of drug resistance in chronic tuberculous empyema. Tuber Lung Dis 1995;76(5):4637.

[19] Hutter JA, Harari D, Bainbridge MV. The management of empyema thoracis by thoracoscopy and irrigation. Ann Thorac Surg 1985;39(6):517-20.

[20] Lemmer JH, Botham MJ, Orringer MB. Modern management of adult thoracic empyema. J Thorac Cardiovasc Surg 1985;90(6):849-55.

[21] Malhotra P, Aggarwal AN, Agarwal R, et al. Clinical characteristics and outcome of empyema thoracis in 117 patients: a comparative analysis of tubercular vs. non tubercular aaetiologies. Respir Med 2007;101(3):423-30.

[22] Kundu S, Mitra S, Mukherjee S, et al. Adult thoracic empyema: a comparative analysis of tuberculous and 
non-tuberculous etiology in 75 patients. Lung India 2010;27(4):196-201.

[23] Hulnick DH, Naidich DP, McCauley DI. Pleural tuberculosis evaluated by computed tomography. Radiology 1983;149(3):759-65.

[24] Automated real-time nucleic acid amplification technology for rapid and simultaneous detection of tuberculosis and rifampicin resistance: xpert MTB/RIF system for the diagnosis of pulmonary and extra pulmonary TB in adults and children: policy update. Geneva: World Health Organization 2013.

[25] Lawn SD, Nicol MP. Xpert ${ }^{\circledR}$ MTB/RIF assay: development, evaluation and implementation of a new rapid molecular diagnostic for tuberculosis and rifampicin resistance. Future Microbiol 2011;6(9):1067-82.

[26] Mukherjee S, Biswas ID. Role of cartridge-based nucleic acid amplification test in diagnosis of tuberculous pleural effusion compared to tuberculous empyema in HIVseronegative patients. Int J Sci Stud 2017;5(6):125-9. 